\title{
Implementation of Yorùbá Language Multimedia Learning System
}

\author{
Safiriyu I. Eludiora and Olamide A. Akinbande \\ Department of Computer Science \& Engineering, \\ Obafemi Awolowo University lle-Ife, Nigeria. \\ eludioraomolola@gmail.com and demgroups@gmail.com
}

\begin{abstract}
The use of multimedia learning system has been widely accepted as a useful and effective tool in the field of human language. Many students and researchers have examined multimedia learning's effectiveness from a number of aspects, including four skills of learning: listening, speaking, reading (including vocabulary comprehensive) and writing. However, the effectiveness of multimedia in human language hasn't been well explained. The goal of this study was to develop a multimedia learning system for a fresh learner of Yorùbá language by introducing the Yorùbá alphabets and their respective words. In particular, this study investigates the relative efficiency of three different modes used in teaching Yorùbá language alphabets, directional complements: text only, text with a still picture and text with audio clips. In other to develop the system, many traditional textbooks, and written theses on Yorùbá alphabets are consulted for effective study of the alphabets and their possible words. Java programming language was used for the implementation of the multimedia platform. After the implementation of this study, the platform will enable users to interact with a desktop and web-based Yorùbá alphabets multimedia environment where easy and effective identification of Yorùbá language alphabets. The platform will teaches on how to pronounce words from Yorùbá language alphabets. In conclusion, Yorùbá alphabet multimedia learning system provides efficient means of writing, reading and speaking Yorùbá language.
\end{abstract}

Keywords: Yorùbá language, Yorùbá alphabets, word formation, Teaching and Learning, Multimedia, Vowels and Consonants

\section{Introduction}

The advent of information and communication technology (ICT) in teaching and learning has witnessed a proliferation of research at all levels of education and training. Initial efforts tended to compare technology-based teaching with more 'traditional' teaching methods with the quasi-experimental design being most popular (Eynon, 2006).

However, of late there is growing realization to investigate deeply into the processes involved in the technology-based learning environment with the aim of illuminating, understanding, and extrapolating to similar situations using qualitative inquiry methods. A compelling reason for the selection of qualitative methodologies is the shift in theoretical emphasis from a more behaviorist perspective of technology application to a more cognitive constructivist view of teaching and learning (Eynon, 2006). 
Safiriyu I. Eludiora and Olamide A. Akinbande; Implementation of Yorùbá Language Multimedia Learning System, Transactions on Machine Learning and Artificial Intelligence, Volume 4 No 6 December, (2016); pp: 1-12

The purpose of this research is to develop a desktop/web-based multimedia learning platform that teaches learners of Yorùbá language on how to identify, pronounce and learning words from Yorùbá language alphabets.

\subsection{Human Language}

Language is highly structured and hierarchically organized. Language users must therefore possess a certain level of cognitive skills or capacities that allow them to comprehend language by decomposing the hierarchically structured units. Over the years, the question which aspects of human language are also found in non-human animal communication systems has been hotly debated (Hauser et al., 2014).

\subsubsection{Yorùbá Language}

Yorùbá is a common language spoken by over 30 million people in the South West of Nigeria (NPC, 2006), but classified by tongues and dialects. From several studies on Yorùbá language, three different variations of the language have been identified:

1. The North-West Yorùbá consists of Ẹgbá (Abẹ́òúta) İbàdàn, Òyọ́, Ògùn, Ấwórì and Lagos.

2. Central Yorùbá- Ìgbómìnà, Yágbà, Ifẹ̀, Èkìtì, Akúrẹ́, Ẹộn and İjẹ̀bú.

3. South East Yorùbá- Òkìtìpupa, Ìlàjẹ, Òndó, Ộộ, Àkókó (İkàrẹe) Șàgámu (İṣágá-Olómù) and parts of İjẹ̀bú.

These dialectic groups speak Yorùbá with slight variation cause by pronunciation in consonants and vowels in the formation of words with minimal impact on semantics. For instance, the north-western Yorùbá town of Ọyọ́-Álaàfin (a savannah situated-metropolitan town) and ìbàdàn (a rain-forest metropolitan city) are known by velar-fricative voice.

A condition caused by partial closure of vocal track, while the lips are left to produce sound. Velar-fricative (one of the two fricatives, the other is stop) is a common feature of Latin/Roman/Greek letters, because many of Greek letters are pronounced by different parts of the mouth (such as " $y$ " represented by ' $\gamma$ ') because of air stoppage which may be (partial or total) as words (or letters) pass through the oral cavity and the mouth. In Yorùbá, some letters like (P, T, K, H, F, and S) fall under this category, as they are pronounced by different parts of mouth such as: lips tongue (front/back) because of vocal track closure.

Table 1 International Phonetic Alphabet

\begin{tabular}{|c|c|c|c|}
\hline IPA & Orthography & Yorùbá & English \\
\hline$[\mathrm{a}]$ & $\mathrm{A}$ & Ká & (fold) \\
\hline$[\mathrm{e}]$ & $\mathrm{E}$ & Kè̀ & (shout) \\
\hline$[\mathrm{e}]$ & $\mathrm{E}$ & Kẹ & (pet) \\
\hline$[\mathrm{i}]$ & $\mathrm{I}$ & Kí & (greet) \\
\hline$[\mathrm{o}]$ & $\mathrm{O}$ & Kó & (gather) \\
\hline$[\mathrm{o}]$ & $\mathrm{O}$ & Kọ́ & (teach) \\
\hline$[\mathrm{u}]$ & $\mathrm{U}$ & Kú & (die) \\
\hline
\end{tabular}

Source: Akinlabi, 2000

\subsection{Yorùbá Alphabet and Grammar}

In this section Yorùbá Alphabets and Grammar are discussed. 


\subsubsection{Yorùbá Alphabet}

Alphabet are twenty-five in numbers, which includes both the seven vowels and eighteen consonant sounds. English and Yorùbá orthographic symbols differ significantly, though the direction of writing of both languages is from left to right thus:

English Capital Letters: A B C D E F G H I J K L M N O P Q R S T U V W X Y Z

English Small Letters: a b c d e f g hij k I m nopqrst u v w xyz

Yorùbá Capital Letters: A B D E E F G GB I H J K L M N O Ọ P R S Ș T U W Y

Yorùbá Small Letters: a b d e ẹ f g gb i h j I m n o ọ p s ș t u w y

The Yorùbá Alphabet has a LATIN-BASED character set just like English. A few letters in English do not occur in Yorùbá Alphabet. They are: Cc, Qq, Vv, Xx and Zz.

On the other hand, three letters in Yorùbá are not in the English alphabet. However, they are variants of letters in English. They are: Ẹe, ọo and Șș.

These three letters incorporate a short vertical bar below. Another acceptable conventional way of representing these three letters is with a 'dot' under, but separate from the main body. These are written like this: Ẹe, Ọo and Ș̣̦.

One other letter that occurs in Yorùbá but not in English is the letter 'GBgb' which is the combination of letters ' $\mathrm{g}$ ' and ' $\mathrm{b}$ ' into one 'character' and is more appropriately termed a diagraph .

\subsubsection{Yorùbá Vowel and Consonant}

Yorùbá has seven oral vowels. By oral it is meant that air escapes from the mouth (rather than from the nose) when the vowel is produced. These seven vowels are contrastive in the sense that switching one of the vowels for the other leads to a change in the meaning of the word. The other categories of vowels are: nasal vowels (an, ẹn, in, ọn and un) and two pure syllabic vowels ( $m$ and n) (Akinlabi, 2000).

Technically, they are called vowel phonemes (Akinlabi, 2000). The seven oral vowels are shown in the following examples below. The equivalent symbols (letters) of the International Phonetic Alphabet (IPA) are put in brackets.

There are differences too in the English and Yorùbá vowel phonemes, thus:

English: /i:/, /i/,/e/, /ae/, /a:/, /J/, /J:/, /u/, /^/,/ə :/, / ə/.

Yorùbá: /a/, /e/, / ẹ /, /i/, / ọ /, /u/.

Consonant sounds are sounds produced by having a partial or complete obstruction in the vocal tract (Akinlabi, 2000). In English and Yorùbá languages, we have the following consonantal sounds:

English: /p/, /b/, /t/, /d/, /k/, /g/, /f/, /y/, /s/, /z/, /h/, /ts/, /dz/, /m/, /n/, /d/, / /, /s/, /l/, /r/, /j/, /w/, /j/ Yorùbá: /b/, /t/, /d/, /k/, /kp/, /gb/, /f/, /s/, /h/, /dz/, /m/, /n/, /r/, /l/, /j/, /w/.

The phonemes that are unique to English are:

$/ \mathrm{q} /, / \mathrm{J} /, / \mathrm{ts} /, / \mathrm{z} /, / \mathrm{J} /, / \mathrm{v} /$

Consonantal phonemes unique too Yorùbá are: 
Safiriyu I. Eludiora and Olamide A. Akinbande; Implementation of Yorùbá Language Multimedia Learning System, Transactions on Machine Learning and Artificial Intelligence, Volume 4 No 6 December, (2016); pp: 1-12

$/ \mathrm{gb} /, / \mathrm{kp} /$ and $/ \mathrm{s} /$.

\subsubsection{Gírámà (Grammar) Yorùbá}

Grammar occupies a prominent place in any spoken language. In fact, grammar provides and sets the rules which govern linguistic behavior of native speakers. Grammar serves as a compass to navigate language trouble waters; should a non-native want to speak a new language, it behooves on him or her to learn the rules and principles guiding such a language, Yorùbá is no exception. Linguists have identified three categories of human language: language form, language meaning and language in context.

Under the language form, Morphology (the formation and composition of words), grammar comes with the (eight parts of speech), Syntax- (formation and composition of phrases/sentences from the words), and semantic (meaning), Phonology (the sound systems) which consists of phonetics (the actual properties of speech sound and also non-speech- which helps in the pronunciation of words and their perceptions.

\section{Review of Related Research}

In this section we reviewed what researchers have done on Yorùbá language endangerment, teaching and learning, and ICT provisions in teaching and learning.

\subsection{Yorùbá Language Endangerment}

Balogun (2015) is of opinion that if urgent steps are not taken by the stakeholders that Yorùbá Language will be endangered. He examined low-usage of the language in some states in South West of Nigeria. The findings show that the students find it difficult to communicate with the people using the Yorùbá language.

Aladesote (2016) examined the factors or variables that are responsible for Yorùbá language endangerment. The results of the study show lack of commitment to indigenous language; habitat displacement, colonial legacy, and defective language planning are responsible to the gradual extinction. The study concluded that the Yorùbá language should be used at home, and it should be a criteria for post primary school admission.

\subsubsection{Use of Mother Tongue for Learning}

Abidogun and Adebule (2013) examined the contributions of mother tongue in pre-Nursery or primary early childhood education. The study raised six issues: language background, situation in Nigeria, policy documentation on language in Nigeria, language theory and development, and problem statement and rationale. Success and failures of mother tongue usage in the country needs to be reviewed in order to address issues mentioned.

Abijo (2014) was of opinion that proper implementation of educational policies in Nigeria will increase the learning of indigenous languages in particular Yorùbá language.

Abidogun (2012) presented it that one of Nigerian educational policies stipulated it that "the first three years of primary education should be taught in learners' mother tongue. The study conducted show that primary school teachers used were able to teach the subjects (like social studies), but with challenges.

Oribar et al (2013) examined which of the Yorùbá language (mother tongue learners) as a medium of instructions and English language as a medium of instructions to teach social studies in the nursery school 
would make the pupils perform excellently well. The experiment was carried out and the results show that the pupils taught with their mother tongue (Yorùbá language) perform better than those that were taught with English language.

\subsection{Learning and Teaching}

Learning is defined as a change in knowledge attributable to experience. Learning involves a change in the learner, learner's knowledge and cause of the change is the learner's experience (Mayer, 2011).

Learning is not measured through one operational definition. Rather, learning is a blend of comprehension, transfer of new material, and the retention of material. In fact, most transfer studies focus purely on the similarities and differences between the contexts of initial learning and subsequent transfer (Butler, 2010). Given the current study, learning has been evaluated using a multimedia device.

\subsection{ICT for Learning and Teaching Yorùbá Language}

\subsubsection{E-Learning System}

Oyekan (2013) proposed the use of E-learning approach to teach and learn the Yorùbá language. He opined that the Information and communication technology (ICT) is a good tool to increase the people's interest in learning the language.

\subsubsection{E-Tutor System}

Adeyanju (2015) developed windows mobile application for learning Yorùbá language. The learner can learn how to read alphabets, numbers and common words in Yorùbá language.

\subsection{Multimedia Learning System}

Multimedia is now spreading through the educational system as a tool for effective teaching and learning. With multimedia, the communication of information can be done in a more effective manner and it can be an effective instructional medium for delivering information.

Multimedia access to knowledge is one of the possibilities of information and communication technology that has tremendous impact on learning. The instructional media have emerged in a variety of resources, and equipment, which can be used to supplement or complement the teacher's efforts in ensuring effective learning by the students.

It is recognised that conventional media technologies can no longer meet the needs of our teaching and learning processes; as a result, they are being replaced by multimedia technology. This technology provides a learning environment that is self-paced, learner-controlled and individualised.

The present day world is marked by significant discrepancies in the development of languages. While some languages are on a steep advance, others are facing endangerment which might lead to extinction. There is need to develop an educational tool to support and strengthen cultural preservation of endangered languages.

Many traditional textbooks have been written that teaches how to read, write and speak Yorùbá language alphabet and words. Hence, this system provides a multimedia learning platform using three multimedia components (image, text and audio) in other to help people who are interested in learning the language to become proficient in writing, reading and speaking. 


\section{System Framework Design}

A system is a layered structure indicating what kind of programs can or should be built and how they would interrelate. A framework may be for a set of functions within a system and how they interrelate.

This simple framework aims to capture the dynamic nature of the requirements model of a Yorùbá multimedia learning system model in which the GUI consist of the menu bar which includes file menu, view menu and the help menu. The file menu consist of home button and the close button. The home button navigate the user to the home page of the Yorùbá Alphabet and the close button exit user out of the system.

The view menu consist of the Yorùbá Alphabet button. The Yorùbá Alphabet button navigate user to where user can view the text and listen to recitation of the Yorùbá Alphabet. The Yorùbá Alphabet interface consist of play, pause, stop and exit button.

The help menu consist of feedback and about button. The feedback button allows the users to send their experience about the system for better improvement of the system. The About button display details about the system.

\subsection{System design}

The design of the system has the basic architecture of a windows application where the applications serve as a link between the user and the library (data base). Design is often thought as a process of putting together things, a process of combination. It is also a guiding principle or technical rule that specifies detailed function of system. It defines the components and subcomponents of system. Firstly, the design will allow the user learn the Yorùbá alphabet using multimedia tools (play, pause, stop and exit). Lastly the system will allow user to click on each of the Yorùbá alphabet and learn different Yorùbá alphabet words with their respective texts, images and sounds.

\subsection{Database design}

We considered the interaction between the text, pictures and sound in the design of our database. The alphabets are used to match the sound with the pictures of possible items in that frame. Figures 1 to 5 show some selected alphabets.

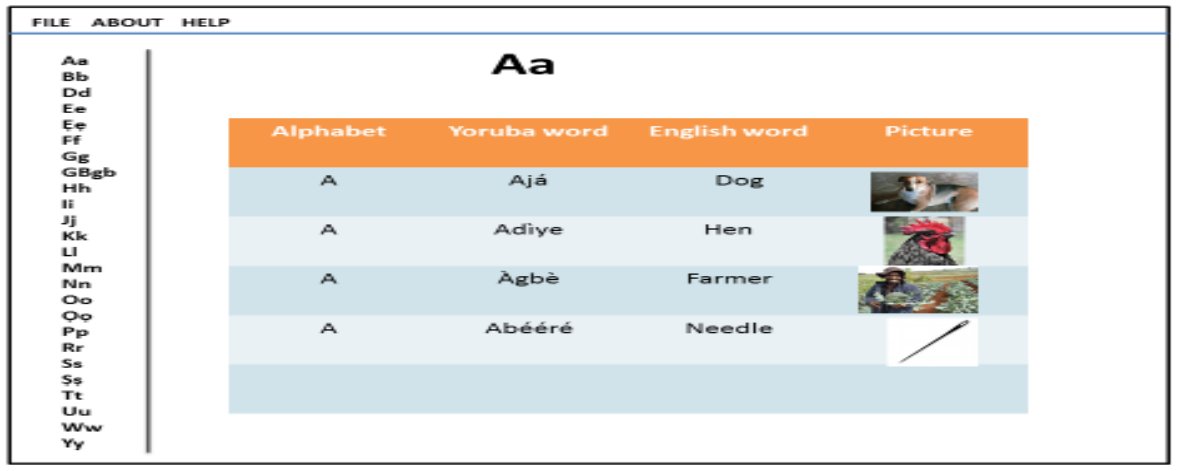

Figure 1 Database layout for Alphabet A 


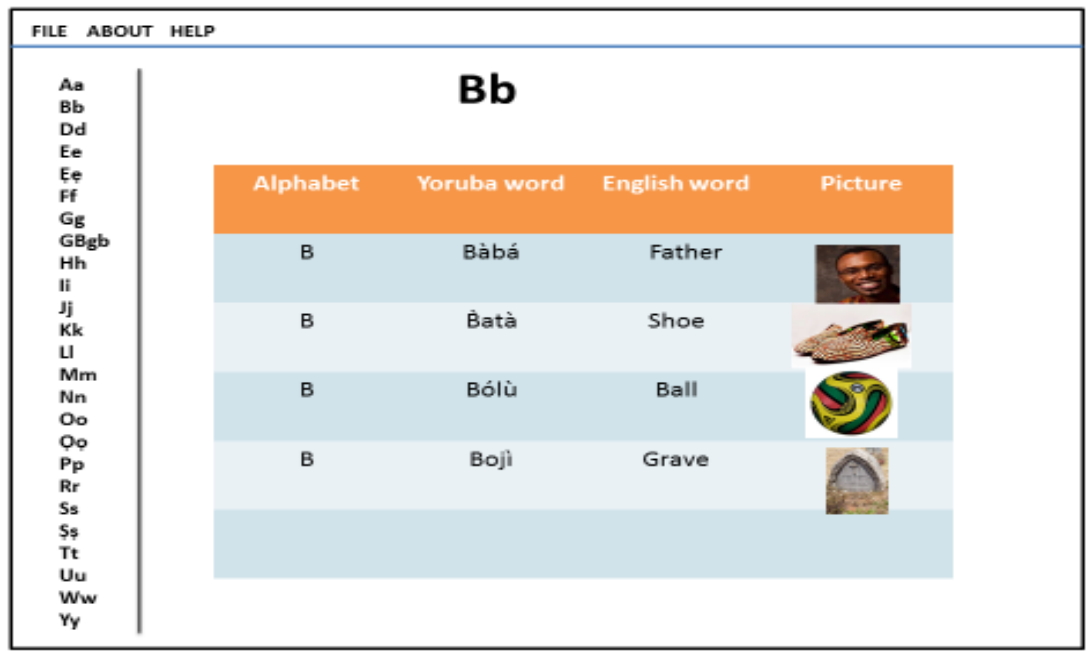

Figure 2 Database layout for Alphabet B

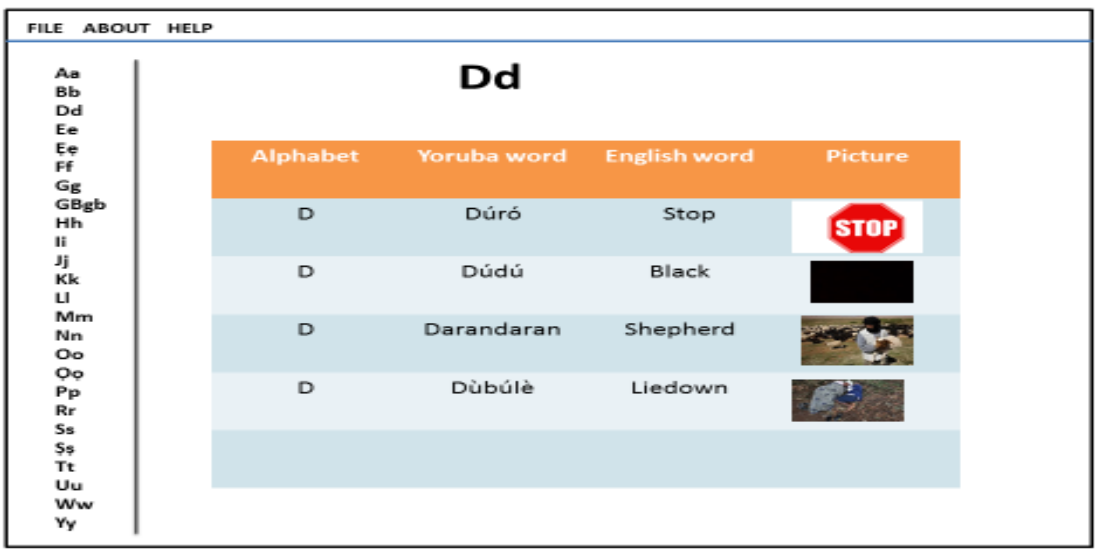

Figure 3 Database layout for Alphabet D

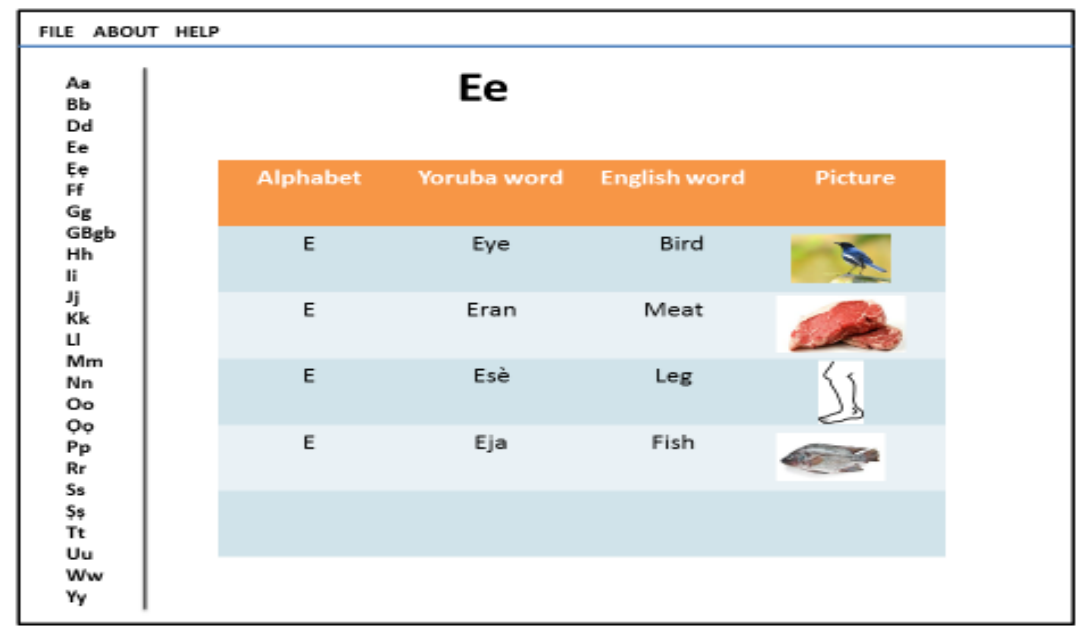

Figure 4 Database layout for Alphabet E 
Safiriyu I. Eludiora and Olamide A. Akinbande; Implementation of Yorùbá Language Multimedia Learning System, Transactions on Machine Learning and Artificial Intelligence, Volume 4 No 6 December, (2016); pp: 1-12

\subsection{Software System Description}

The system provides a multimedia platform for Yorùbá alphabet where (text, image and audio) are used as a multimedia tools for the development of the learning system. The system provides an interface where Yorùbá alphabet can be learned using the three multimedia tools (text, image and audio). The system also provides an interface where Yorùbá alphabet pictorial can be studied. The interface consists of each Yorùbá alphabet words with their respective images and audios. The system will be described according to the content format (both source and target format), user interface (which include the system output and samples GUI), use case diagram and performance.

The program was writing with java programming language. IntelliJIDEA, a Java integrated development environment (IDE) for developing computer software is the software environment used for implementing the multimedia learning and the framework for the design of the learning system is JavaFX. Java FXML, an XML-based declarative markup language for constructing a JavaFX application user interface is used for the design of the learning system graphical user interface (GUI) for the system controller while for the front end known as the GUI was developed using Java FXML. The multimedia learning has a page for the Yorùbá alphabet and each Yorùbá alphabet consists of a page that displayed Yorùbá words and respective images of the words. The system contains a database where the images and audios for the Yorùbá words are fetched using a controller as an intermediary between the database and the GUI.

\subsubsection{Software Design}

Algorithm is a logical sequence of steps for solving a problem, often written out as a flow chart that can be translated into a computer program as used in this study. Sequence diagrams are often used to depict the chronologically-structured event flow through a use-case. A class diagram is a type of static structure diagram that describe the structure of a system by showing the system classes, their attributes, operations (or methods), and the relationships among the classes.

The class diagram has five (5) modules (menu, GUI, button, alphabet database and sound database) each element in the class diagram have relationship with each other. The blocks in the class diagram contains attributes and methods that interacts together. The class diagram explains the illustration and interaction of the elements in each class.

\section{System Implementation Framework}

The system is implemented as described in the use case diagram shown in figure 5 , system inputs, system outputs, and giving some samples GUI, and its performance. A use case diagram at its simplest is a representation of a user's interaction with the system that shows the relationship between the user and the different use cases in which the user is involved. A use case diagram can identify the different types of users of a system and the different use cases and will often be accompanied by other types of diagrams as well.

Use case diagrams could be regarded as being twofold - they are both behavior diagrams (because they describe behavior of the system), and they are also structure diagrams - as a special case of class diagrams where classifiers are restricted to be either actors or use cases related with association.

The use case diagram in figure 5 below explained the activities between the users and the system. There are two (2) users interacting with different activities in the system. The users are; 
1. The User: The user in the use case diagram is the main actor in the system. The user interact with all the activities from the running of the system, clicking of tabs, learning and sending feedbacks about the system's behavior.

2. The Administrator (Admin): The Admin is the manager of the system. The admin oversee the performance of the system and modify the system based on the user's feedbacks.

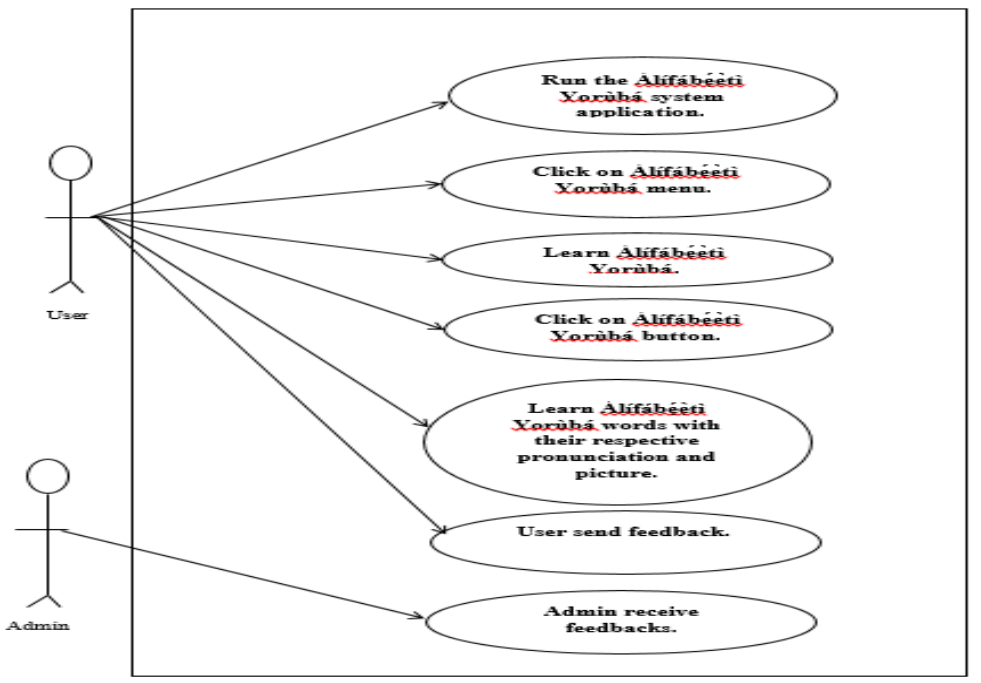

Figure 5 the system use case diagram

\subsection{System implementation}

The system input is provided with a button on homepage of the system GUI which navigate user to the multimedia interface of the learning system. It supplies the user with all the Yorùbá alphabet with their images and audios for each alphabet. The view menu on the GUI contains Yorùbá alphabet button which display Yorùbá alphabet. The system input and output are shown in figure 6 and figure 7. System output defines communication with the outside world which in this case is the human or user of the system. The system provides two different output; one for the Yorùbá alphabet and the second for Yorùbá alphabet pictorial. The Yorùbá alphabet displayed the Yorùbá alphabet and the Yorùbá alphabet pictorial displayed each Yorùbá alphabet words and their images and audios associated with the words. Some of the system outputs are shown in figure 8 to figure 9 and figure 10 is the system feedback plane.

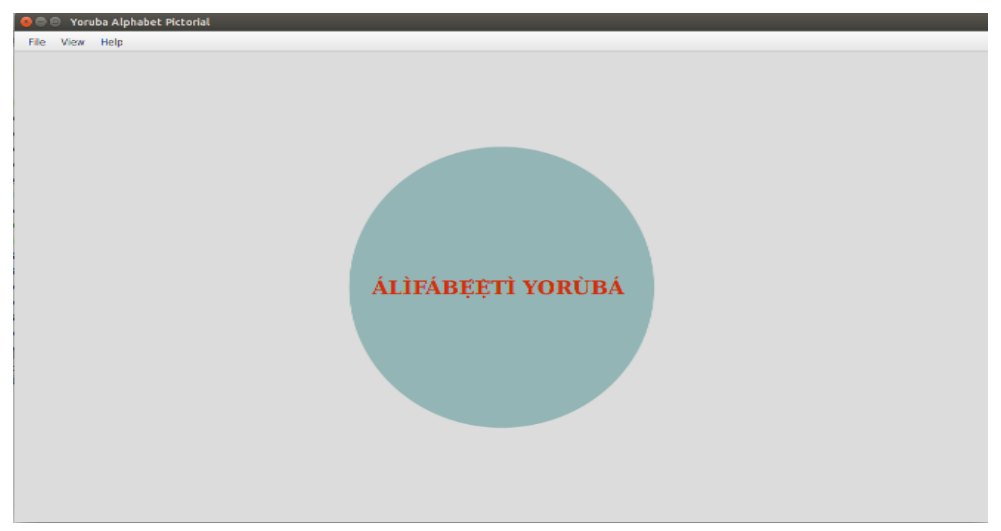

Figure 6 System GUI showing one input of the Yorùbá alphabet interface 


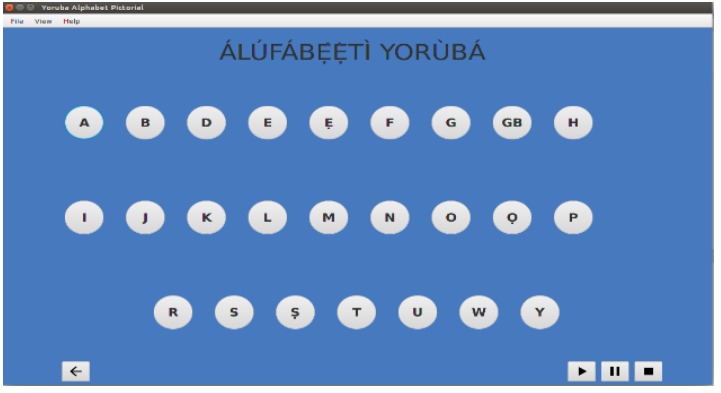

Figure 7 System output containing the Yorùbá alphabets

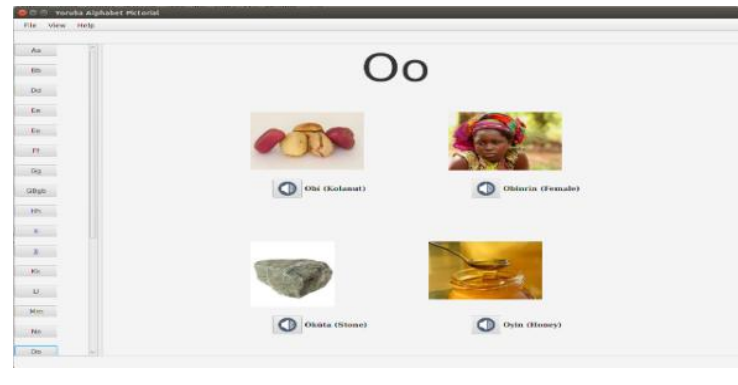

Figure 9 Oo Alphabet Sample

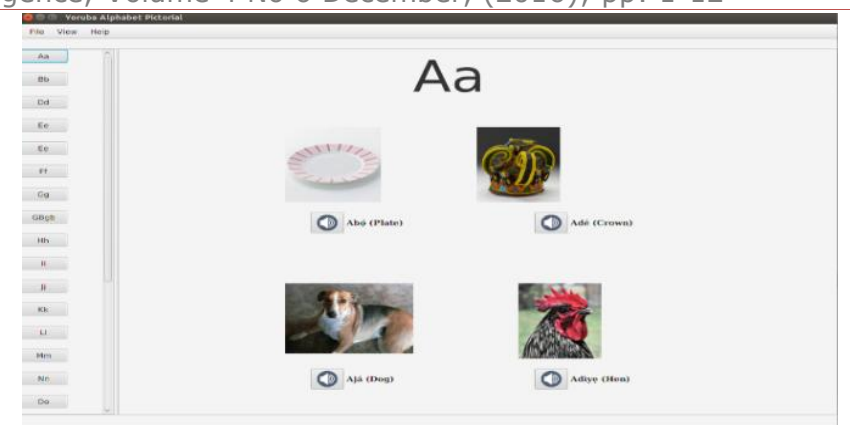

Figure 8 Aa Alphabet Sample

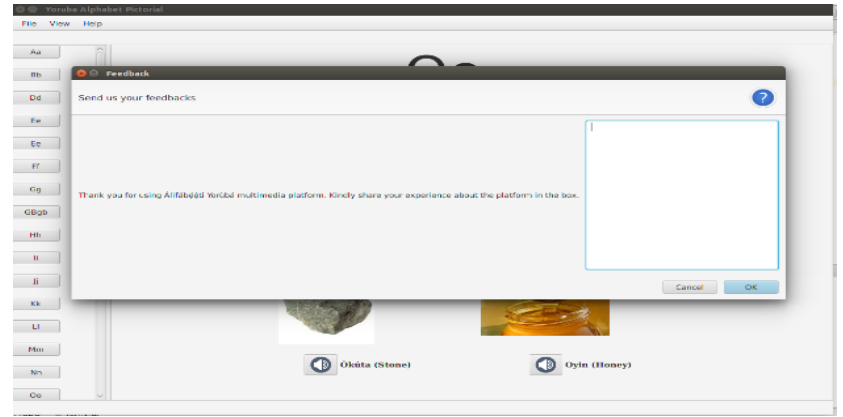

Figure 10 system feedback

\section{Yorùbá Language Word Formation}

This application can be used to teach or learn how to form words. The two, three, four, and five letters words can be formed. We he equally provided the syllable of each word formed. Examples are shown in tables 2 to 5 .

\begin{tabular}{|c|c|c|c|c||c|c|c|c|c|}
\hline \multicolumn{9}{|c|}{ Table 2 Two letters' words } & \multicolumn{5}{c|}{ Table 3 three letters word } \\
\hline Example & $\begin{array}{c}\text { Part of } \\
\text { speech }\end{array}$ & syllable & $\begin{array}{c}\text { No. of } \\
\text { syllables }\end{array}$ & $\begin{array}{c}\text { English } \\
\text { meaning }\end{array}$ & Example & $\begin{array}{c}\text { Parts of } \\
\text { Speech }\end{array}$ & syllable & $\begin{array}{c}\text { No of } \\
\text { syllable }\end{array}$ & $\begin{array}{c}\text { English } \\
\text { meaning }\end{array}$ \\
\hline dè̀ & verb & dè̀ & 1 & 'to be soft' & Àbá & noun & À/bá & 2 & Suggestion \\
\hline șé & verb & șé & 1 & 'to break' & Abà & noun & A/bà & 2 & Barn \\
\hline rò & verb & rò̀ & 1 & 'to think' & Àbí & conjunction & À/bí & 2 & Or \\
\hline kú & verb & kú & 1 & 'to die' & Abo & adjective & A/bo & 2 & Female \\
\hline rù & verb & rù & 1 & 'to carry' & Àbọ & noun & À/bọ & 2 & Arrival \\
\hline
\end{tabular}

Table 4 three letters words

\begin{tabular}{|c|c|c|c|c|}
\hline Example & $\begin{array}{c}\text { Part of } \\
\text { speech }\end{array}$ & syllable & $\begin{array}{c}\text { No of } \\
\text { syllable }\end{array}$ & $\begin{array}{c}\text { English } \\
\text { meaning }\end{array}$ \\
\hline Àdán & noun & $\grave{A} /$ dán & 2 & bat \\
\hline Àfín & noun & $\grave{A} /$ fín & 2 & albino \\
\hline agbọ̀n & noun & a/gbọ̀n & 2 & basket \\
\hline Ahọn & noun & $\mathrm{A} /$ họn & 2 & tongue \\
\hline
\end{tabular}


Table 5 four letter words

\begin{tabular}{|c|c|c|c|c|}
\hline Example & Part of speech & Syllable & $\begin{array}{c}\text { No of } \\
\text { syllable }\end{array}$ & $\begin{array}{c}\text { English } \\
\text { meaning }\end{array}$ \\
\hline Àbaja & noun & $\grave{A} / \mathrm{ba} / \mathrm{ja}$ & 3 & Facial marks \\
\hline Abájọ & interjection & $\mathrm{A} / \mathrm{bá} / \mathrm{jọ}$ & 3 & $\begin{array}{c}\text { Expressing } \\
\text { surprise }\end{array}$ \\
\hline Abàmi & adjective & $\mathrm{A} / \mathrm{bà} / \mathrm{mi}$ & 3 & strange \\
\hline Àbámọ̀ & noun & $\grave{A} / \mathrm{bá} / \mathrm{mọ}$ & 3 & regret \\
\hline Abẹ̀bẹ & noun & $\mathrm{A} / \mathrm{bẹ̀} / \mathrm{bẹ}$ & 3 & fan \\
\hline
\end{tabular}

\section{Conclusion}

In recent times an increasing number of Yorùbás are taking up residence abroad either temporarily, but for extended periods of time, or permanently. In a way, they are joining the descendants of their forebear's cousins of generations past, people of Yorùbá heritage in Brazil, Cuba, Trinidad \& Tobago, all over the Caribbean and indeed a great many others scattered worldwide.

Most of Yorùbá language grammar textbooks are literature textbooks. Tone marking, numbers and some other grammar related topics are not included.

In other to ensure the long term survival of the Yorùbá language and culture in the generations unborn, there is need for the Yorùbá learners and Yorùbá language teachers of today to have modern learning tools and resources at their disposal which will help them appreciate their root or origin. This learning system is essential to convey aspects of Yorùbá language in the writings and to incorporate themes familiar to the reader to attract and sustain their interest.

\section{FUTURE WORK}

In future we will address key issues about Yorùbá language grammar teaching and learning. The work is on- going on the Mobile application.

\section{REFERENCES}

[1] Eynon, R. (2006). The use of ICTs for teaching and learning in Law Education: some innovators' perspectives. Web Journal of Current Legal Issues, (Web JCLI), Issue 3.

[2] Hauser, M. D., Yang, C., Berwick, R. C., Tattersall, I., Ryan, M. J., Watumull, J. Lewontin, R. C. (2014). The mystery of language evolution. Frontiers in psychology, 5.

[3] Butler, A. C. (2010). Repeated testing produces superior transfer of learning relative to repeated studying. Journal of Experimental Psychology, 36(5), 1118-1133.

[4] Mayer, R. E. (2011). Applying the science of learning. Boston, MA: Pearson.

[5] Abijo, J.A. (2014). Emerging trends in the use of Mother-Tongue as a Language of instruction in lower Nigerian Primary Schools, Journal of Emerging Trends in Educational Research and Policy studies, Vol 5 (8) pp 124-127. URL: 
Safiriyu I. Eludiora and Olamide A. Akinbande; Implementation of Yorùbá Language Multimedia Learning System, Transactions on Machine Learning and Artificial Intelligence, Volume 4 No 6 December, (2016); pp: 1-12 http://jeteraps.scholarlinkresearch.com/articles/EMERGING\%20TRENDS\%20IN\%20THE\%20USE\%200F\% 20MOTHER.pdf Abijo [Accessed: 09/24/26]

[6] Abidogun, B.G. and Adebule, O.I. (2013) Contributions of Mother Tongue Education in early childhood Education, 1st Annual International Interdisciplinary Conference, Portugal Proceedings, pp 267-272 URL: http://eujournal.org/files/journals/1/articles/1337/public/1337-4340-1-PB.pdf [Accessed: 09/24/26]

[7] Oyekan, A.A. (2013) E-learning solutions for Language Teaching and Learning: Yoruba Language, International Conference "ICT for Language Learning, URL: http://conference.pixelonline.net/ICT4LL2013/common/download/Abstract_pdf/150-ELE12-ABS-Abiodun-ICT2013.pdf [Accessed: 09/24/26]

[8] Oribabor, O.A. and Adesina A.D.O. (2013) Mother Tongue Instruction and Academic Achievement of pupils in Nursery Schools, International Research Journals of Arts and Social Sciences, Vol 2(5), pp131-133 URL: $\quad$ http://www.interesjournals.org/full-articles/mother-tongue-instruction-and-academicachievement-of-pupils-in-nursery-schools.pdf?view=inline [Accessed: 09/24/26]

[9] Adegoju, A. (2009) Language Teaching, Learning and Utility: A Triadic Paradigm for Revitalising Indigenous Nigerian Languages, issue 27, pp 1-11, URL:

https://www.researchgate.net/publication/237777896_Language_Teaching_Learning_and_Utility_A_Tri adic_Paradigm_for_Revitalising_Indigenous_Nigerian_Languages [Accessed: 09/24/26]

[10] Balogun, T.A. (2013) An endanger Nigerian Indigenous Language: The case of Yoruba Language, African Nebula issue 6, pp 70-82, URL: http://nobleworld.biz/images/6-Balogun_s_Paper.pdf [Accessed: 09/24/26]

[11] Aladesote, O.I., Johnson, O.V. and Agbelusi, O. (2016) Selection of Factors Responsible for Yoruba Language Extinction using Feature Extraction Techniques, Pyrex Journals of Educational Research Reviews, Vol 2(1), pp 001-005, URL: http://www.pyrexjournals.org/pjerr/pdf/2016/january/aladesote-etal.pdf [Accessed: 09/24/26]

[12] Adeyanju, I.A., Omotosho, O.I. and Fatunde, B.M. (2015) Development of a Yoruba Language E-Tutor for Windows phone, African Journal of Computing and ICT Vol 8 No. 3, pp 135-140, URL: http://www.ajocict.net/uploads/V8N3P15-2015_AJOCICT.pdf [Accessed: 09/24/26]

[13] Abidogun, B.G. (2012) Teachers Experiences of using Yoruba as a Medium of Instruction in Primary Classes: Implications for Learning, Unpublished Ph.D Thesis University of Pretoria, South Africa, pp 1-229, URL:

http://repository.up.ac.za/bitstream/handle/2263/31910/Abidogun_Teachers(2013).pdf?sequence=1 [Accessed: 09/24/26]

[14] National population commission, 2006 census: URL: www.population.gov.ng (accessed: 25/06/2012).

[15] Akinlabi, A. (2000) Understanding Yoruba Life and Culture Africa Word Press INC, Trenton, New Jersey 08607.URL: http://www.rci.rutgers.edu/ akinlabi/Yoruba-Sound-System.pdf [Accessed: 04/10/2016] 